Final submitted version of paper subsequently published as: Gedye, S., Dismore, H., Muneer, R. and Cotton, D.R.E (2019) Damage Limitation: Learning lessons from Complaints and Appeals Staff on the Handling of Student Grievance. Higher Education Policy.

\title{
Damage Limitation: Learning lessons from Complaints and Appeals Staff on the Handling of Student Grievance
}

\begin{abstract}
Against a backdrop of rising student complaints in higher education (HE) and debate about students as consumers, increasing attention is turning to institutional processes for dealing with complaints and appeals. This paper draws on a nationwide survey across UK HE to explore the unique experiences of Complaints and Appeals staff. The research provides important new insights into the perceived benefits of student complaints as well as the challenges. The findings indicate a need to change the culture around complaints to help address issues such as time taken to resolve formal complaints, expectations of students, and impact on student/staff relationships. Drawing on theoretical models of service failure from the business sector, combined with a co-production model of $\mathrm{HE}$, we conclude with recommendations about how complaints and appeals might be regarded as a learning opportunity leading to improved channels of communication and dissemination, as well as offering continuing professional development opportunities.
\end{abstract}

Keywords: Higher education, complaint, appeal, consumer, co-production

Wordcount: 6681 
Final submitted version of paper subsequently published as: Gedye, S., Dismore, H., Muneer, R. and Cotton, D.R.E (2019) Damage Limitation: Learning lessons from Complaints and Appeals Staff on the Handling of Student Grievance. Higher Education Policy.

\section{INTRODUCTION}

The aim of this research was to examine the unique experiences of Complaints and Appeals staff at UK universities and to determine how lessons learnt might shape future practice. This is timely given a steady increase in the number of complaints received by the Office for the Independent Adjudicator (OIA), an external ombudsmen tasked with resolving student complaints in $\mathrm{HE}$. The reasons for this trend are currently unclear. We therefore consider potential influences, including tuition fees and the concept of students as consumers, before exploring the impact of these on complaint handling procedures. Finally, we turn to the gap in empirical research on Complaints and Appeals processes and specifically, a need to examine staff experiences.

\section{Trends in student complaint behaviour}

The OIA defines a complaint as 'an expression of dissatisfaction by one or more students about a provider, action or lack of action, or about a standard of service provided by or on behalf of the provider', whereas an academic appeal is described as 'a request for a review of a decision of an academic body charged with making decisions on student progress, assessment and awards' (OIA, 2016a, 8). Whilst there is a technical difference made between a complaint and an appeal, the principles underlying practice in both areas are similar (OIA, 2016a, 7). Given that complaints and appeals are both expressions of dissatisfaction, this paper refers to all actions as a complaint unless the data specifically refer to an appeal.

In 2007 the number of student complaints received by the OIA was 734 , rising to a peak of 2,040 in 2014 . The number of complaints received by the OIA fell slightly between 2014 and 2016 . This reversal may be attributed to the impact of the Good 
Final submitted version of paper subsequently published as: Gedye, S., Dismore, H., Muneer, R. and Cotton, D.R.E (2019) Damage Limitation: Learning lessons from Complaints and Appeals Staff on the Handling of Student Grievance. Higher Education Policy.

Practice Framework introduced in 2014 (2016a) and providers resolving more complaints internally (Behrens, 2015; OIA, 2016b). However, the latest data from the 2017 Annual Report (OIA, 2018) show that, once more, there is a small increase in complaints coming to the OIA with 1,635 new complaints received, compared to 1,517 in 2016. It is important to recognise that the OIA figures are only a proxy for student dissatisfaction, representing only those formal complaints unresolved at an institutional level. The true extent of complaint within higher education is hidden.

\section{Tuition fees}

Increases in complaints have traditionally been linked to a highly marketised system and the rise in tuition fees (Millward, 2016). In the UK, the Higher Education Act 2004 raised tuition fees to $£ 3000$ from 2006 , a three-fold increase in the maximum amount universities could charge students compared to previous years. Then in 2012 the cap was raised to $£ 9000$ (and raised again to $£ 9250$ in 2017). Although governmentfunded student loans (repayable after graduation) are available, the increase in student awareness of the costs of higher education may have impacted on their behaviours in a whole range of ways. However, there is little empirical evidence to support the claim that higher fees in the UK have led directly to the rise in complaints (Millward, 2016). Rather, indirect evidence suggests an increasingly instrumental approach to education by students, linking poor educational outcomes and potentially damaged employability with a tendency to complain (Temple et al, 2014).

\section{Students as consumers}

Closely associated with the rise in fees, there has been growing discourse and debate around the university as a marketised business and students as consumers 
Final submitted version of paper subsequently published as: Gedye, S., Dismore, H., Muneer, R. and Cotton, D.R.E (2019) Damage Limitation: Learning lessons from Complaints and Appeals Staff on the Handling of Student Grievance. Higher Education Policy.

(AMOSSHE, 2013; Woodall et al, 2014; Tomlinson, 2014; Nixon et al, 2016; Bunce et al, 2017; Canning, 2017). On the one hand, some researchers have noted the positive changes a consumer model could bring about in educational institutions - forcing universities to become more accountable for the way their programmes are delivered and recognizing the need to evolve with changing requirements as students begin to perceive education as an investment (McMillan and Cheney, 1996). On the other hand, the student-as-consumer model has been criticized for downplaying - even ignoring the responsibilities of a student in the educational process. The 'co-production model' (McCulloch, 2009) has been offered as an alternative to the student-as-consumer. Supported by research in the business sector, customers involved in the co-production and delivery of services have been shown to produce milder responses to service failure (Botti and McGill, 2011).

An important aspect of the debate around students as consumers is the student voice agenda (Canning, 2017) with an emphasis on students providing feedback on their university experiences. Module and programme evaluations have existed for several decades, but more recently, the National Student Survey (NSS) which runs across UK HE (often alongside in-house questionnaires) has had a dominant influence, particularly given its contribution to the core metrics used in the Teaching Excellence Framework (TEF). Other countries with highly marketised HE systems include the USA, Canada, Australia and New Zealand and to a lesser extent the Netherlands (Brown, 2010, 17). Some of these countries also operate national student surveys, such as the Australian Survey of Student Engagement (AUSSE) in Australia, the National Student Survey (NSE) in the Netherlands, and in the USA, for those colleges that choose to participate, the National Survey of Student Engagement (NSSE). 
Final submitted version of paper subsequently published as: Gedye, S., Dismore, H., Muneer, R. and Cotton, D.R.E (2019) Damage Limitation: Learning lessons from Complaints and Appeals Staff on the Handling of Student Grievance. Higher Education Policy.

HEls (and academic staff) are fully aware of the impact of the NSS through the TEF and league tables that are intended to act as a guide to quality for prospective students when selecting an institution or course. However, many academics remain wary of measuring the quality of education by student satisfaction, and there are a number of well-evidenced issues with student feedback reliability including that of gender bias (Boring et al., 2016). For some, the risk of using student feedback to judge quality is that it may instead undermine quality. Furedi (2011) for example, warns of the rise of 'defensive education', where academic learning is compromised (for instance by revising grading procedures or teaching styles) in order to keep students satisfied and complaints low.

It is important to bear in mind that whilst OIA figures provide the headlines for student complaints, these data represent only those complaints made to universities not resolved at an institutional level. As such they are the tip of a pyramid of student dissatisfaction, as conceptualised by Cooper-Hind and Taylor $(2012,57)$. At the base of the pyramid, and representing the largest pool of dissatisfaction, are those students who are unhappy but do not raise their dissatisfaction with the university. This group may make their unhappiness known through negative word-of-mouth and through unfavourable feedback in module/course evaluation. Bolkan and Goodboy (2013) differentiate between expressive dissent (venting class-specific frustrations in order to feel better and gain sympathy), vengeful dissent (spreading negative publicity about a staff member to damage his/her credibility) and rhetorical dissent (directly persuading a staff member to fix apparent wrongdoings to perform better in class). Research on student behaviour indicates that students do not always complain directly to the university or approach the staff involved, making use of other options instead. For 
Final submitted version of paper subsequently published as: Gedye, S., Dismore, H., Muneer, R. and Cotton, D.R.E (2019) Damage Limitation: Learning lessons from Complaints and Appeals Staff on the Handling of Student Grievance. Higher Education Policy.

example they might complain privately to friends and family or other third parties, or make 'invisible complaints', such as changing their attitude towards the organization or shifting their loyalty (Hart and Coates, 2010). There is a concern that such complaints may lead to reputational damage (Millward, 2016).

\section{Complaint-handling procedures}

All HEls have their own internal complaints and appeals processes for those students who wish to complain formally. These will differ in specifics between institutions but follow a similar set of guiding principles in line with OIA good practice guidance (OIA, 2016a). In the first stage, students are encouraged to resolve complaints by approaching tutors, supervisors or programme committees. Should they remain dissatisfied or if they prefer not to approach the subject of their complaint directly, they can submit a formal complaint to the university. Further, students can ask for any decision made through the Complaints and Appeals process to be reviewed by a Complaints Review Panel. Only when a settlement has not been reached and students wish to pursue the issue further, should they be encouraged to approach the OIA.

The OIA guides and trains universities on good practice to avoid misunderstandings in student-university relationships and achieve an early resolution. Students can submit complaints to the OIA only once they have been through each stage of their university's internal procedures. The OIA can decide a case is justified, partly-justified, not justified or - when no longer relevant or out of the jurisdiction of areas decided upon by the OIA - not eligible. In addition, the OIA might also try to settle disputes between the student and university by suggesting courses of action that have not yet been attempted or mediate between them. If a university did not comply, they would be named for non-compliance in the OIAs annual report (OIA, 2017). 
Final submitted version of paper subsequently published as: Gedye, S., Dismore, H., Muneer, R. and Cotton, D.R.E (2019) Damage Limitation: Learning lessons from Complaints and Appeals Staff on the Handling of Student Grievance. Higher Education Policy.

Four main concerns with these procedures have been highlighted by previous research. Firstly, the internal processes and timescales followed by different institutions vary, compromising the level of transparency and fairness with which complaints may be treated. In particular, some students perceived internal complaint procedures to be biased towards the university (NUS, 2009). Secondly, the OIA has been criticized for insisting on written processes and denying students the opportunity to speak in public hearings (Dalziel, 2011). Thirdly, Dalziel (2011) questioned the genuine independence of a body which is funded by universities: the OIA insist that, although they are funded by the universities, the way that they are funded does not influence the decisions they make. Lastly, the time taken to close cases has been an issue. The OIA attempts to resolve all but the most complex complaints brought to it within 90 days. However, at the institutional level, time was found to be the topmost reason why students decide against submitting complaints (Cooper-Hind and Taylor, 2012), seemingly contrary to the QAA's (2013) demand for fair, accessible and timely procedures.

In the USA and Canada, institutions operate their own independent ombuds systems, with no national accountability. According to Harrison (2007), complaints to ombuds have grown in numbers, with significant increases in the 1980s. In Australia and New Zealand complaints are handled in a similar way to the OIA system in England and Wales. Both countries have institutional complaints handling processes, but in cases where the outcome has not been satisfactorily resolved, students may have the right to take the complaint to a national quality assurance agency. In Australia unresolved student complaints are handled by the Tertiary Education Quality and Standards Agency (TEQSA) and in New Zealand by the New Zealand Qualifications Authority 
Final submitted version of paper subsequently published as: Gedye, S., Dismore, H., Muneer, R. and Cotton, D.R.E (2019) Damage Limitation: Learning lessons from Complaints and Appeals Staff on the Handling of Student Grievance. Higher Education Policy.

(NZQA). However, none of these systems appear to offer the same level of transparency of reporting on complaints as that given by the OIA in the UK.

As this section shows, there is some literature on students' complaint-related behaviour and perceptions of complaint procedures, but much less is known about the unique experiences of Complaints and Appeals staff at UK universities. We argue that future practices should be shaped by the lessons learnt from these real-world experiences and seek to achieve this aim via the following research questions:

1. What are Complaints and Appeals staff perceptions of the potential benefits of student complaints for HEls and teaching practice?

2. What are Complaints and Appeals staff perceptions of the potential challenges of student complaints for HEls and teaching practice?

3. Can the ways that complaints are used to improve practice be made more effective?

\section{METHODS}

This paper focuses on learning from the experiences of Complaints and Appeals staff in UK higher education institutions. Ethical approval was granted for the study from the authors' institution and an online questionnaire was developed using the Survey Monkey tool. The questionnaire was piloted with critical friends, refined and then emailed to the 'Practitioners Group for Student Complaints and Appeals' who are within the Academic Registrars' Council (ARC) professional body. An online questionnaire was considered the most appropriate vehicle for the survey as it enabled anonymity and allowed the questionnaire to be distributed nationally across the sector. 
Final submitted version of paper subsequently published as: Gedye, S., Dismore, H., Muneer, R. and Cotton, D.R.E (2019) Damage Limitation: Learning lessons from Complaints and Appeals Staff on the Handling of Student Grievance. Higher Education Policy.

Potential participants were provided with survey information including assurances about confidentiality, withdrawal and consent.

The questionnaire consisted of closed and open questions eliciting quantitative and qualitative responses. In total 59 valid responses were received. These consisted of $57 \%$ from post-92 institutions, and $43 \%$ from pre-92 institutions. The sample was dominated by respondents from England (89\%), with $8 \%$ from Scotland and 3\% from Wales. The gender split of respondents was $72 \%$ females and $28 \%$ males. Tables 1 to 3 highlight how these response percentages compare to percentages for the sector according to institution type, country and gender. It can be seen from these comparisons that the responses are reasonably representative of the wider sector.

\section{INSERT TABLES 1 to 3 HERE}

Respondents provided answers to the survey questions based on their overall experience of Complaints and Appeals, encompassing all students on undergraduate, postgraduate taught and research programmes. Qualitative responses to the survey were initially thematically coded in relation to the stated research objectives using NVivo. These codes were reviewed, allowing emergent themes to be added, before the full qualitative data set was analysed, using the constant comparative method to draw out cross-cutting themes (Clarke and Braun, 2017).

\section{FINDINGS AND DISCUSSION}

In this section, we report key findings from the study, and compare them to previous research on student complaints. Themes emerging from the analysis are provided in italics below each question. As an opening question, respondents were also asked 
Final submitted version of paper subsequently published as: Gedye, S., Dismore, H., Muneer, R. and Cotton, D.R.E (2019) Damage Limitation: Learning lessons from Complaints and Appeals Staff on the Handling of Student Grievance. Higher Education Policy.

about the types of student complaints most commonly experienced. This provides a useful context for the questions that follow and responses are summarised below.

Within this study, Complaints and Appeals staff reported that the most common student complaints concerned:

- Course content and delivery (76\%)

- Individual staff (43\%)

- Thesis/dissertation supervision (40\%)

With respect to appeals, the top 3 areas were:

- Mitigating circumstances (83\%)

- $\quad$ Marking (74\%)

- Degree classification (66\%)

These areas of concern all relate to teaching quality and student performance (as opposed to aspects such as fees and facilities). This concurs with OIA data that the most common complaints relate to academic status (OIA, 2018) and studies reporting that the top causes for student complaints are factors directly related to teaching and course development, such as management of the class, contact time, quality of instruction and lecturers' attitudes towards students (Lala and Priluck, 2011; Hart and Coates, 2010).

\section{What are Complaints and Appeals staff perceptions of the potential benefits of student complaints for HEls and teaching practice?}

In the words of Complaints and Appeals staff, the ability to complain about practice and to appeal decisions serves a number of beneficial purposes, with $54 \%$ of 
Final submitted version of paper subsequently published as: Gedye, S., Dismore, H., Muneer, R. and Cotton, D.R.E (2019) Damage Limitation: Learning lessons from Complaints and Appeals Staff on the Handling of Student Grievance. Higher Education Policy.

respondents offering exemplification of positive consequences of student complaint. Two key themes were evident in the responses. Respondents predominantly noted how complaints and appeals provided an opportunity to learn and improve practice. They also spoke in terms of the fairness and accountability they afforded.

\section{Contributes to improvements in institutional policy and practices}

Complaints and Appeals staff frequently spoke about the positive impacts of complaint as leading to improvements in practice because complaints 'highlighted bad practice' and therefore gave an opportunity to 'reflect on our practices and processes'. As one respondent put it:

'We always know more at the end of a complaint than we did at the beginning so they are always an opportunity to improve'

Improvements to policies and processes were often cited as being a beneficial outcome of complaints. Respondents were invited to elaborate on this with $58 \%$ of respondents providing specific examples of how a complaint had changed university policy or processes. Policy changes included changing the wording of policies and specifically improving policies around assessment, fitness to practice, mitigating circumstances, and to a lesser extent, supervision. The most commonly identified changes to process related to the need for improved record keeping, better communication of information to students, and consistent and accurate application of university policy and process. In some cases, individual staff members were involved, with interventions such as: 'the management of the programme was moved', 'a teaching team being changed', and the requirement to place staff under 'performance review. In many cases, improved communication to students is a key part of the 
Final submitted version of paper subsequently published as: Gedye, S., Dismore, H., Muneer, R. and Cotton, D.R.E (2019) Damage Limitation: Learning lessons from Complaints and Appeals Staff on the Handling of Student Grievance. Higher Education Policy.

enhancement. This is also a recommendation put forward by other researchers investigating complaints (Millward, 2016; Douglas et al, 2015).

When operating effectively, the ability to complain offers a mechanism by which lessons can be learnt and practice improved:

'In any complaint or appeal that we feel deserves to be fully or partially upheld, we will always have a plan for how we will change processes going forward to ensure that the standard is raised and other students do not have a similar experience.'

The following quote from one respondent highlights the complex interplay of university procedures, individual circumstances and emotions:

'I think they are extremely positive, despite the emotions involved....It allows us to see policies and procedures from a student perspective and in doing so, we can streamline them to be more user friendly, or clearer, or even fairer.... It allows for personal circumstances to be considered.'

Respondents also spoke about the positive impacts of complaints contributing to 'continuous improvement', 'challenging thinking about existing processes', ensuring 'consistency', and of militating against complacency by 'keeping us on our toes'. Where this had been taken seriously, the impact on complaints could be considerable:

'A professional suitability case highlighted many aspects of the university's policy which weren't in line with principles of natural justice. The policy was completely revised, and we have received fewer appeals as a result'. 
Final submitted version of paper subsequently published as: Gedye, S., Dismore, H., Muneer, R. and Cotton, D.R.E (2019) Damage Limitation: Learning lessons from Complaints and Appeals Staff on the Handling of Student Grievance. Higher Education Policy.

As $\mathrm{Xu}$ et al. (2014) argue, although service failure puts the relationship between student and university to the test, it also offers an opportunity to address wider issues when a student complains, as exemplified by the following quote by a respondent:

'Shows you the areas that need work, you can monitor patterns and trends to see if there are any recurrent problems.'

\section{Offer fairness and accountability}

In addition to improving practice, respondents felt that complaints also offered justice to students in terms fairness and accountability. A system of complaints and appeals gives:

'a mechanism to ensure that students who have genuine circumstances get a fair outcome'

Complaints therefore provide fairness so that, where fault is found, there is redress the ability 'to right a wrong'. They were also considered beneficial in 'ensuring equity of treatment'.

There was a sense that providing students with the opportunity to complain 'allows the student to have a voice', in order to 'show that we do listen to what students say'. As one Complaints and Appeals staff respondent put it, this:

'shows the university as receptive to criticism and enables the university to act transparently'.

In this way complaints are seen to provide accountability in addition to fairness. Complaints were therefore seen as an essential part of good governance of an 
Final submitted version of paper subsequently published as: Gedye, S., Dismore, H., Muneer, R. and Cotton, D.R.E (2019) Damage Limitation: Learning lessons from Complaints and Appeals Staff on the Handling of Student Grievance. Higher Education Policy.

institution and when felt to be valid, a reasonable and appropriate response by students.

\section{What are Complaints and Appeals staff perceptions of the potential challenges of student complaints for HEls and teaching practice?}

Whilst many examples showed how complaints contributed to improving practice, over one third of the survey sample (36\%) articulated negative consequences. Four themes were prominent within the qualitative responses. These were impacts in relation to 1) time, 2) expectations, 3) complexity and 4) emotions/relationships.

\section{Complaints take too much staff time}

A commonly voiced negative impact associated with student complaints was staff time, particularly when the complaint was viewed as unfounded or 'petty'. The time taken to handle problems was spoken of in terms of being 'disproportionate' as represented by the comment ' $1 \%$ of students taking up $99 \%$ of staff time'. This is in part because complaints processes require significant effort in pulling together large amounts of evidence, regarded by some as 'excessive information'. Awareness by staff about the time-consuming nature of dealing with complaints may itself have negative impacts on good practice as demonstrated by the following quote:

I do believe that some appellants, if sufficiently persistent/exhaustive in their use of the process, can encourage overworked academic respondents simply to 'roll over' and support appeals because it will be less time consuming.' 
Final submitted version of paper subsequently published as: Gedye, S., Dismore, H., Muneer, R. and Cotton, D.R.E (2019) Damage Limitation: Learning lessons from Complaints and Appeals Staff on the Handling of Student Grievance. Higher Education Policy.

Arguably, the dominance of time as a theme in the data indicates the importance of universities attempting to resolve issues at the earliest stage to avoid escalation, as emphasised in the Good Practice Framework (OIA, 2016a).

\section{Student expectations}

When asked why students complain, Complaints and Appeals staff frequently spoke about students having: unrealistic expectations; an awareness of the right to complain and increased acceptability of complaining; frustrations with university processes; and a customer mentality due to the payment of fees. This echoes the findings of Millward (2016) and an AMOSSHE (2013) paper noting an increasing expectation of students to receive personalised support and the need to provide students with a personalised service. Yet significantly, many of the respondents offered value judgements about the nature of the complaint, as to whether it was genuine or not. Genuine dissatisfaction with process or outcomes was considered reasonable - when students complained about injustice, perhaps because of poor service or discriminatory treatment.

Commonly though, the opinion voiced for the reasons driving these appeals relates to students 'desperately' trying to 'rescue themselves' (with the implication that their appeal was unfounded):

'Students are often looking for someone to 'blame' for the fact that they have not achieved higher grades/classification. Student expectations can be too high.'

One reason for this may be that, as Tomlinson (2014) and Bunce et al (2017) point out, some students who do not identify strongly as learners may have a higher consumer orientation. In other words, students finding themselves with low grades 
Final submitted version of paper subsequently published as: Gedye, S., Dismore, H., Muneer, R. and Cotton, D.R.E (2019) Damage Limitation: Learning lessons from Complaints and Appeals Staff on the Handling of Student Grievance. Higher Education Policy.

may exhibit more instrumental approaches to learning and dissatisfaction with their

HE experience. Yet caution is also needed when students do not feel that their complaints have been treated seriously. As Bolkan and Goodboy (2013) found, many complaints can escalate when staff exhibit an inability (or unwillingness) to facilitate the process.

External pressure on students to obtain higher degree classifications was also recognised by Complaints and Appeals staff. For example:

'Having the 'right' degree or classification is more critical than ever for employment/further study.'

As reported by Temple et al (2012), the increasing emphasis on employability is prompting staff to encourage students to think about employment outcomes. This in turn may be causing students considerable anxiety about their employment prospects and is another major factor related to student satisfaction (Douglas et al, 2015). So, whilst Complaints and Appeals staff considered the process absolutely necessary and important, the right to complain had led to some unrealistic expectations. One respondent noted that the process could act as a 'venting system' for aggrieved students who may not have valid reasons for complaint. It was clear that some Complaints and Appeals staff had witnessed students with 'false hope' who thought that if they appealed then they will 'automatically get a favourable outcome'.

\section{Complaints can lead to increasing complexity of processes}

Whilst about half of respondents felt that complaints could have positive impacts for the institution (59\%), a similar number of respondents also noted that complaints sometimes led to unwelcome changes (54\%), typically in procedures and language, 
Final submitted version of paper subsequently published as: Gedye, S., Dismore, H., Muneer, R. and Cotton, D.R.E (2019) Damage Limitation: Learning lessons from Complaints and Appeals Staff on the Handling of Student Grievance. Higher Education Policy.

with these being driven in the direction of being more formal, legalistic and increasingly complex in an attempt to cover all eventualities:

'Complaints which are justified inevitably lead to reviews of systems and procedures. There is a danger that new and more intrusive systems are introduced leading to more complicated administration.'

These comments are of interest because they conflict with the ideal that complaints present an opportunity to make policy more streamlined, fairer and clearer (OIA, 2016a). Whilst this may be a positive outcome in some cases, the consequence of complaints may cause greater complexity.

\section{Complaints can lead to negative emotions and relationships}

The adverse emotional territory caused by students complaining and appealing decisions was a strong theme in the data. Sometimes it was recognised that the process could resolve misunderstandings and improve relationships, particularly where early resolution and mediation was involved, as emphasised in the OIA Good Practice Framework (2016a). However, in many cases, respondents described damaging feelings and behaviours. Participants described 'mistrust', tension' and 'irretrievable breakdown' in relationships, with staff finding it hard not to take complaints 'personally'. Impact was seen as especially damaging if the complaint was considered to be 'unfounded', 'malicious' or 'vexatious' leading to staff feeling particularly 'demoralised', 'disempowered', 'demotivated', 'disheartened' and 'fearful'.

Some concerns were raised about the culture of complaints causing staff and students to adopt potentially deleterious behaviours. Comments were made that 'trust has gone 
Final submitted version of paper subsequently published as: Gedye, S., Dismore, H., Muneer, R. and Cotton, D.R.E (2019) Damage Limitation: Learning lessons from Complaints and Appeals Staff on the Handling of Student Grievance. Higher Education Policy.

in the relationship between students and lecturers' and that staff are now more 'circumspect' and have more 'formality' in their interactions:

'There's this feeling that students are complaints waiting to happen instead of seeing them as people first and then fee-paying students second.'

Complaints and Appeals staff mentioned staff having more 'defensive' attitudes and more 'rigid' approaches to working with students, which were in turn seen as having undesirable consequences for student support:

'Some academic staff are increasingly becoming less willing to go the extra mile...Instead, they are tending to stick to a prescriptive level of what is expected of them....the staff-student relationship is tending towards a transactional paradigm over a purely educational one.'

The defensive and distrustful aspect of relationships was also exemplified through student behaviour:

'we have an increase in students trying to record staff and use this against them later in a complaint, which makes lecturers worried.'

Such behaviour, facilitated by technology can engender:

'a feeling that everything you say may be taken down and used in evidence against you'.

Previous research has identified a tension between a consumer mind-set and education. Naidoo et al. (2011) note that risk-taking does not sit easily with a learning relationship based on passive consumerism in which there is an assumption that qualifications will follow in return for specified levels of work and a fee. Xu et al. (2014) 
Final submitted version of paper subsequently published as: Gedye, S., Dismore, H., Muneer, R. and Cotton, D.R.E (2019) Damage Limitation: Learning lessons from Complaints and Appeals Staff on the Handling of Student Grievance. Higher Education Policy.

note the need for a combination of competence, communication and time to repair the relationship between university and student after a complaint.

Finally, in addition to damaged relations between students and staff, Complaints and Appeals staff also commented on how it could influence their relationships with colleagues:

'It's tough working in Complaints and Appeals - the students hate you as they see you as being responsible for any negative outcome, and the staff hate you for even existing in the first place.'

These experiences exemplify why it is difficult to change institutional culture so that complaints are treated positively to improve practice.

Can the ways that complaints are used to improve practice be made more effective?

\section{Learning lessons from early resolution of informal complaints}

The detection and rectification of problems at an early stage to avoid formal disputes was identified as one way in which complaints could be handled better. Respondents recognised that student-facing staff (particularly academics) felt they were 'under the spotlight, sometimes without a right of reply' and that as a consequence a rising number of staff were seeking support at an early stage:

'Increasingly, we are seeing staff coming to us at the earliest instance of a complaint/appeal. Whilst we consider this a positive thing because ... we are able to foresee and advise on good practice in handling the early stages of a 
Final submitted version of paper subsequently published as: Gedye, S., Dismore, H., Muneer, R. and Cotton, D.R.E (2019) Damage Limitation: Learning lessons from Complaints and Appeals Staff on the Handling of Student Grievance. Higher Education Policy.

complaint/appeal, we have noticed an increase in the level of reassurance academic and administrative staff need as they are 'terrified' of 'getting it wrong"

Whilst there are some positive elements noted here, $51 \%$ of respondents indicated that their institution had no mechanism for monitoring informal complaints, thus recording and improving early-stage complaint resolution appears to be an area which could be significantly enhanced:

informal complaints are not recorded or disseminated as well as they should be. This gives an early opportunity to rectify any problems or errant processes and we are missing an opportunity.'

The varied responses to this question reveal diverse practice across the sector. For some, monitoring of informal complaints took the form of periodic harvesting of existing data such as that in school reports, module reviews, and informal complaint tracking logs. Who does this monitoring is unclear. It is not necessarily stated in the data and responses were often vague - sometimes this is 'done centrally' (by Complaints and Appeals Staff?) and sometime by 'management'. Some departments specifically asked for annual information on informal complaints received but this was in very general terms, such as trends of areas of complaints'.

Some respondents spoke about systems they had in place that allowed ongoing monitoring. These included:

- being kept abreast of informal complaints by being copied into emails sent to students confirming the outcome of an informal appeal;

- being sent local appeal outcome forms which allow 'constant informal review during the year to spot trends and take action if required; 
Final submitted version of paper subsequently published as: Gedye, S., Dismore, H., Muneer, R. and Cotton, D.R.E (2019) Damage Limitation: Learning lessons from Complaints and Appeals Staff on the Handling of Student Grievance. Higher Education Policy.

- the use of a central university email account from which complaints can be referred to the relevant area which 'whilst it doesn't capture all informal complaints (we accept this wouldn't be possible), it does provide an indication of what's going on and where the 'flurries' are occurring;

- monitoring students who approach Student Services that are considering making a formal complaint.

One respondent remarked that students who formally complain/appeal must have attempted to resolve their complaint via the informal process first and, 'this enables us to look at why the complaint was not able to be resolved at the informal stage'.

The literature highlights the importance of encouraging rhetorical not vengeful dissent and framing it in terms of developing constructive skills of arguing and negotiating (Bolkan and Goodboy, 2013). Bolkan and Goodboy also emphasise the importance of early resolution of issues and recommend creating opportunities for anonymous feedback and mid-semester evaluations. The OIA (2016a) suggests questions to consider in attempting early resolution such as 'can it be resolved by providing, where appropriate, an explanation, an alternative solution or an apology?' Early resolution also seems preferable given that attentiveness and communication of staff is key to student satisfaction (Douglas et al, 2015). Failure to respond appropriately risks 'double deviation' whereby the original complaint is handled so badly the customer feels it necessary to escalate to a manager, or 'triple deviation' when this extra layer of complaint also meets with an unsatisfactory response (Millward, 2016; Casado-Diaz and Nicolau-Gonzalbez, 2009).

Given its importance in terms of the UK Teaching Excellence Framework and HE League Tables, respondents were specifically asked if they knew how informal 
Final submitted version of paper subsequently published as: Gedye, S., Dismore, H., Muneer, R. and Cotton, D.R.E (2019) Damage Limitation: Learning lessons from Complaints and Appeals Staff on the Handling of Student Grievance. Higher Education Policy.

negative comments made through the National Student Survey (NSS) were looked at and used by their institution, with $79 \%$ responding positively. Replies indicated that this data-set was usually examined at a local level by schools/departments and responded to through action plans. It may also be examined centrally though NSS working groups and via other central/senior committee and reporting structures. Complaints and Appeals staff, however, appeared to have little direct engagement with NSS data, representing a missed opportunity to connect institutional learning between various forms of student feedback.

\section{Improving the effectiveness of complaint-related enhancement}

The perspective of Complaints and Appeals staff offers important insight into how institutions and individuals can handle complaints. $81 \%$ of the sample group felt that complaints could be used more effectively to improve practice, strongly indicating room for improvement in handling dissatisfaction. Whilst respondents noted many examples of changes made to specific institutional policies and practices, there remains scope for improvement in most universities, particularly around the following issues:

- Revising policies to aid clarity and student-friendliness without increasing complexity

- Better communication to students about the changes made to practice in the light of complaints

- Improved dissemination and training of staff, including discussion of (anonymised) cases, outcomes, and lessons learned in order to benefit a wider audience beyond those immediately affected. 
Final submitted version of paper subsequently published as: Gedye, S., Dismore, H., Muneer, R. and Cotton, D.R.E (2019) Damage Limitation: Learning lessons from Complaints and Appeals Staff on the Handling of Student Grievance. Higher Education Policy.

Regarding the latter point, Douglas et al (2016) emphasise the importance of attentiveness (helpfulness) and availability of staff. Addressing standards through improvements to staff support was reflected in comments on mentoring and training such as 'helped to identify gaps in mentoring for new academic colleagues', 'additional training for supervisors' and 'more disability awareness training'. The OIA framework (OIA, 2016a) attempts to support the needs of dissemination and training by providing case studies, better handling of informal complaints as well as changing institutional cultures which concurs with recommendations made more widely in the literature (Bolkan and Goodboy, 2013; Douglas et al, 2015).

Twin barriers of lack of time and money were highlighted by several respondents as reasons inhibiting improvements to practice. However, others indicated where improvements had been made:

'we have now set up a dedicated office to work on the way in which we followup on the findings of appeals and complaints and ensure that they are used to better inform practice'.

Additional improvements noted by respondents included the use of student conciliators who had 'assisted in minimising this impact' and the need for 'strong emphasis on case handlers being independent and impartial'.

\section{Changing the culture}

A major way in which Complaints and Appeals staff suggested that the positive impact of complaints could be harnessed is around attitudinal change. In order to benefit fully from institutional learning about complaints, a cultural change is needed which situates complaints as an opportunity for feedback and enhancement rather than being viewed 
Final submitted version of paper subsequently published as: Gedye, S., Dismore, H., Muneer, R. and Cotton, D.R.E (2019) Damage Limitation: Learning lessons from Complaints and Appeals Staff on the Handling of Student Grievance. Higher Education Policy.

negatively and defensively. Attitudinal aspects of treating complaints in a positive way were implicit in some of the responses but explicitly referred to by others:

'I try hard to present complaints in a positive way - as a learning opportunity rather than as an opportunity to point the long finger of blame.'

This positive response to student complaints is important given that institutions may spend considerable time responding to interrogations about grades and handling formal grievance cases (Gynnild, 2011). Indeed, Bolkan and Goodboy (2013) found that dissent over decisions was highly dependent on the perceived reaction to complaints, with students caring whether the complaint is met in a positive or negative manner. They recommend that the organisational climate needs to be such that staff frame students 'speaking up' as a constructive activity.

Some respondents observed that academic staff can display an unwillingness to learn from complaints, and some senior managers viewed complaints as an annoyance. Bolkan and Goodboy (2013) claim that this attitude can lead to more formal complaints and argue that institutions need to promote tolerance of different points of view. Such sentiments were evident in the opinions of some of the respondents:

If they were seen as an opportunity rather than a penalty. They give a good source of feedback on how things could be improved and if a culture was developed in which people were responsive to these, rather than defensive of the status quo, they would feed more easily into enhancement work.'

I feel there is a distinct barrier between the outcome of an appeal/complaint and the willingness of academic staff to learn from the process ... where you have a handful who are combative at every stage of the process, and who feel it is 
Final submitted version of paper subsequently published as: Gedye, S., Dismore, H., Muneer, R. and Cotton, D.R.E (2019) Damage Limitation: Learning lessons from Complaints and Appeals Staff on the Handling of Student Grievance. Higher Education Policy.

an attack on them personally then you are unlikely to see any change in practice'.

How to create a different culture around staff attitudes to student complaints is therefore something that needs to be addressed within improvement plans.

\section{CONCLUSION}

This research has examined the experiences and perceptions of Complaints and Appeals Staff about how student grievance is handled and what we can learn from this. The main benefits of complaints (and appeals) processes were perceived to be the fairness and accountability that such systems offer, and any improvements made to institutional policy and practices. The key challenges identified were the staff time required for responding to student complaints; the difficulties of managing unrealistic student expectations; the increasing complexity of policies and processes (e.g. lengthening of guidance documents as text is added to cover all eventualities); and the negative emotions and impact on relationships that complaining can lead to. Complaints and Appeals staff believed that complaint processes could be made more effective by achieving more early resolution of complaints, making complaintdriven enhancements more effective, and improving the culture around complaints. These suggestions are in accord with the OIA Good Practice Framework (OIA 2016,a).

Our research suggests that the extent to which institutions learn from complaints is somewhat ambiguous. As Casado-Diaz and Nicolau-Gonzalbez (2009) explain, failure to deliver satisfaction every time is inevitable in almost all services, but the recovery process is key to avoiding harmful consequences. Indeed, the Dearing Report (1997) 
Final submitted version of paper subsequently published as: Gedye, S., Dismore, H., Muneer, R. and Cotton, D.R.E (2019) Damage Limitation: Learning lessons from Complaints and Appeals Staff on the Handling of Student Grievance. Higher Education Policy.

into Higher Education notes that there will inevitably be occasions when students will be dissatisfied, but that concerns should be dealt with fairly and transparently. Many changes in organisational culture have already taken place, especially in making student-facing activities more coherent from the student perspective (Temple et al, 2014). However, as this paper shows, there does not yet seem to have been the same attention paid to complaints and appeals. Institutions and staff need to respond to complaints in a way that avoids double or triple deviation (Casado-Diaz and NicolauGonzalbez, 2009) and confront the many challenges raised in this paper.

One of the challenges is the emotional impact of complaints upon staff and ultimately relationships between staff and students (and relationships between Complaints and Appeals staff and other staff). This is in part because staff may feel insulted by a complaint which will inevitably put strain on relationships. As Nixon et al (2016) warned, this might be compounded by a more marketised HE that calls for more staff emotional labour and even potential risk of exploitation. However, students need to express dissatisfaction as part of a normal process and to expect a positive reaction (Millward, 2016) so that early resolution can be reached, and formal interventions avoided.

Maximising opportunities for early resolution may help in terms of the time taken for complaints and appeals to be processed. However, as warned by Bunce et al. (2017), universities should not unthinkingly implement changes in response to feedback from students as this may risk academic standards. This may pertain particularly with respect to appeals involving student progress, assessment and awards. However, greater clarity for students on assessment processes and procedures can only be beneficial. 
Final submitted version of paper subsequently published as: Gedye, S., Dismore, H., Muneer, R. and Cotton, D.R.E (2019) Damage Limitation: Learning lessons from Complaints and Appeals Staff on the Handling of Student Grievance. Higher Education Policy.

In the business sector, softer and milder responses to service failures have been found when customers are involved in the co-production and delivery of services. One approach is therefore to encourage student involvement in the service of $\mathrm{HE}$, akin to McCulloch's (2009) co-production approach. However, the difficulty of encouraging this kind of relationship within a heavily and increasingly marketised sector should not be under-estimated. Any such approach must be carefully managed to ensure the continuation of higher-level learning and maintenance of strong student/staff relations.

In conclusion, this research alerts us to the importance of using complaints and complaints data more effectively, creating a more positive culture for students and staff. Professional development opportunities for staff include: setting and managing student expectations; addressing emotional responses to complaints; improving the staff-student relationship; encouraging and managing opportunities for early resolution; and enhancing communication. By moving in this direction, institutions would be providing a genuine response to student concerns, addressing the causes and not simply the procedural aspects of complaints. Clearly, improvements around complaints and appeals practice have multiple benefits. These are not just in reducing the headline figures for the number of complaints reported to the OIA but also in fewer complaints escalating within an institution, and the costs associated with this.

On behalf of all authors, the corresponding author states that there is no conflict of interest. 
Final submitted version of paper subsequently published as: Gedye, S., Dismore, H., Muneer, R. and Cotton, D.R.E (2019) Damage Limitation: Learning lessons from Complaints and Appeals Staff on the Handling of Student Grievance. Higher Education Policy.

\section{REFERENCES}

Association of Managers of Student Services in Higher Education (AMOSSHE) (2013) Future of Student Life and Services: Are Students Customers? Discussion paper, 17 April 2013.

Behrens, R. (2013) Three cheers for Lord Leveson: Independent self-regulation newspapers and universities compared. Position Paper 1, Office of the Independent Adjudicator, in association with the Higher Education Policy Institute.

Behrens, R. (2015). 'Sailing on the Boundless and Bottomless Sea: a view from the OIA Bridge', Perspectives: Policy and Practice in Higher Education, 19 (1): 4-9.

Bolkan, S. and Goodboy, A. (2013) 'No complain, no gain: students' organisational, relational and personal reasons for withholding rhetorical dissent from their college instructors', Communication Education 62 (3): 278-300.

Boring, A., Ottoboni, K. and Stark, P., 2016. Student evaluations of teaching (mostly) do not measure teaching effectiveness. ScienceOpen Research.

Botti, S. and McGill, A. (2011) 'The locus of choice: personal causality and satisfaction with hedonic and utilitarian decisions', Journal of Consumer Research 37 (6): 1065-1078.

Brown, R. (2011) 'The March of the Market', in Molesworth, M., Scullion, R. and Nixon, M.(eds.) The marketisation of higher education and the student as consumer, Routledge, pp11-25.

Bunce, L., Baird, A. and Jones, S. (2017) 'The student-as-consumer approach in higher education and its effects on academic performance', Studies in Higher Education, 42 (11): 1958-1978Canning, J. (2017) Conceptualising student voice in UK higher education: four theoretical lenses, Teaching in Higher Education, 22(5): 519-531.

Casado-Diaz, A. and Nicolau-Gonzalbez, J. (2009) 'Explaining behaviour in double deviation scenarios: the banking services', The Services Industries Journal, 29 (12): 1659-1668.

Clarke, V. and Braun, V. (2017) 'Thematic analysis', The Journal of Positive Psychology, 12(3): 297-298.

Cooper-Hind, H. and Taylor, J. (2012). 'Student complaints: an accurate measure of student dissatisfaction?', Higher Education Review, 44(3): 54-80.

Dalziel, G. (2011) 'Complaints against higher education establishments - an evaluation of recent reform', The Law Teacher, 45 (1): 114-120. 
Final submitted version of paper subsequently published as: Gedye, S., Dismore, H., Muneer, R. and Cotton, D.R.E (2019) Damage Limitation: Learning lessons from Complaints and Appeals Staff on the Handling of Student Grievance. Higher Education Policy.

Dearing, R. (1997) Higher Education in the Learning Society: report of the National Committee of Inquiry into Higher Education. London: HMSO.

Department for Business, Innovation and Skills (DBIS) (2016) Success as a Knowledge Economy: Teaching Excellence, Social Mobility and Student Choice. London: DBIS.

Douglas, J.A., Douglas, A., McClelland, R.J. and Davies, J. (2015) 'Understanding student satisfaction and dissatisfaction: an interpretive study in the UK higher education context', Studies in Higher Education, 40 (2): 329-349.

Furedi, F. (2011) 'Introduction to the marketization of higher education and the student as consumer' in Molesworth, M., Scullion, R. and Nixon, M. (eds.) The Marketisation of Higher Education and the Student as Consumer, pp.1-9.

Gynnild, V. (2011) 'Student Appeals of Grades: a comparative study of university policies and practices', Assessment in Education: principles, policy and practice, 18 (1): 41-57.

Harrison, T. R. (2007). 'My professor is so unfair: Student attitudes and experiences of conflict with faculty', Conflict Resolution Quarterly, 24(3): 349-368.

Hart, D. J. and Coates, N.F. (2010) International Student Complaint Behaviour: how do East Asian Students Complain to Their University? Journal of Further and Higher Education 34 (3): 303-319.

Higher Education Statistics Agency (HESA). 2019. Higher Education Staff Statistics: UK, 2016/17. [ONLINE] Available at: https://www.hesa.ac.uk/news/18-012018/sfr248-higher-education-staff-statistics. [Accessed 16 January 2019].

Lala, V. And Priluck, R. (2011) 'When students complain: an antecedent model of students' intention to complain', Journal of Marketing Education 33(3): 236-252.

McCulloch, A. (2009) 'The Student as Co-producer: learning from public administration about the student-university relationship', Studies in Higher Education 34(2): 171-183.

McMillan, J. and Cheney, G. (1996) 'The Student as Consumer: implications and limitations of a metaphor', Communication Education 45(1): 1-15.

Millward, C. (2016) 'Student complainants - vexatious or vulnerable?' Perspectives, Policy and Practice in Higher Education 20(4): 137-142.

Naidoo, R., Shankar, A. and Veer, E. (2011) 'The consumerist turn in higher education: Policy aspirations and outcomes', Journal of Marketing Management, 27(11-12): 1142-1162, 
Final submitted version of paper subsequently published as: Gedye, S., Dismore, H., Muneer, R. and Cotton, D.R.E (2019) Damage Limitation: Learning lessons from Complaints and Appeals Staff on the Handling of Student Grievance. Higher Education Policy.

Nixon, E., Scullion, R. and Hearn, R. (2016) 'Her Majesty the Student: marketised higher education and the narcissistic (dis)satisfactions of the student-consumer', Studies in Higher Education, 43(6): 927-943.

NUS (2009) Review of Institutional Complaints and Appeals Procedures in England and Wales.

https://www.nus.org.uk/PageFiles/350/Complaints\%20Report\%20-\%20Final\%2015.0 2.09\%20Pdf.pdf, accessed 15 October 18.

OIA (2009). Report of OIA Student Survey 2009. London: OIA.

OIA (2016a) The Good Practice Framework: handling student complaints and academic appeals. Revised 2016. OIA.

OIA (2016b) Office of the Independent Adjudicator Annual Report 2016, OIA.

OIA (2017) Compliance with OIA Recommendations and Requests for Information during an OIA Review. http://www.oiahe.org.uk/media/89385/compliance-andrequests-for-information.pdf, accessed 16 October 2018.

OIA (2018) Annual Report 2017 http://www.oiahe.org.uk/media/121920/oia-annualreport-2017.pdf, accessed 15 October 2018.

QAA (2013) UK Quality Code for Higher Education, Chapter B9: academic appeals and student complaints (April 2013).

Temple, P., Callender, C., Grove, L. and Kersh, N. (2014) Managing the Student Experience in a Shifting Higher Education Landscape. York: The Higher Education Academy.

The Complete University Guide (2019) [ONLINE] Availble at: http://www.thecompleteuniversityguide.co.uk/. [Accessed 16 January 2019].

Tomlinson, M. (2014) Exploring the Impacts of Policy Changes on Student Attitudes to Learning. York: Higher Education Academy.

UKUNI (2019). Types of UK Universities. [ONLINE] Available at: http://www.ukuni.net/. [Accessed 16 January 2019].

Woodall, T., Hiller, A. and Resnick, S. (2014) 'Making Sense of Higher Education: students as consumers and the value of the university experience', Studies in Higher Education, 39(1): 48-67.

Xu, Y., Tronvoll, B. and Edvardsson, B. (2014) 'Recovering Service Failure through Resource Integration', The Service Industries Journal, 34(16): 1253-1271. 
Final submitted version of paper subsequently published as: Gedye, S., Dismore, H., Muneer, R. and Cotton, D.R.E (2019) Damage Limitation: Learning lessons from Complaints and Appeals Staff on the Handling of Student Grievance. Higher Education Policy.

\section{ACKNOWLEDGEMENTS}

We would like to thank Huw Morris and lain Rowan of the practitioners group on Student Complaints and Appeals for the Academic Registrars Council (ARC) for their valuable feedback in developing the questionnaire and circulating it to their community. 
Final submitted version of paper subsequently published as: Gedye, S., Dismore, H., Muneer, R. and Cotton, D.R.E (2019) Damage Limitation: Learning lessons from Complaints and Appeals Staff on the Handling of Student Grievance. Higher Education Policy.

Table 1. The proportion of respondents to this survey by institution type, compared to the proportions for the sector in the UK

\begin{tabular}{|l|l|l|}
\hline & This study & Sector $^{*}$ \\
\hline Pre 92 Universities & $43 \%$ & $33 \%$ \\
\hline Post 92 Universities & $57 \%$ & $67 \%$ \\
\hline
\end{tabular}

*Based on data from UKUNI and The Complete University Guide 
Final submitted version of paper subsequently published as: Gedye, S., Dismore, H., Muneer, R. and Cotton, D.R.E (2019) Damage Limitation: Learning lessons from Complaints and Appeals Staff on the Handling of Student Grievance. Higher Education Policy.

Table 2. The proportion of respondents to this survey by UK country, compared to the proportions for the sector.

\begin{tabular}{|l|l|l|}
\hline & This study & Sector \\
\hline England & $89 \%$ & $83 \%$ \\
\hline Northern Ireland & $0 \%$ & $2 \%$ \\
\hline Scotland & $8 \%$ & $11 \%$ \\
\hline Wales & $3 \%$ & $5 \%$ \\
\hline
\end{tabular}

*Based on data in The Complete University Guide 
Final submitted version of paper subsequently published as: Gedye, S., Dismore, H., Muneer, R. and Cotton, D.R.E (2019) Damage Limitation: Learning lessons from Complaints and Appeals Staff on the Handling of Student Grievance. Higher Education Policy.

Table 3. The proportion of respondents to this survey by gender, compared to the gender proportions for the sector in the UK*

\begin{tabular}{|l|l|l|}
\hline & This study & Sector \\
\hline Female & $72 \%$ & $66 \%$ \\
\hline Male & $28 \%$ & $34 \%$ \\
\hline
\end{tabular}

*Based on HESA data for 2016/17 on staff (excluding non-academic atypical) by academic contract marker and activity standard occupational classification. The categories included that potentially relate to staff working in Complaints and Appeals roles were: Managers, directors and senior officials; Professional Occupations; Associate professional and technical occupations; and Administrative and secretarial occupations. 